Research Article

\title{
The Use of Mathematical Analysis in the Nursing Bed Design Evaluation
}

\author{
Zhi-yong Zhou $\mathbb{D}^{1,2}$ Jian-ming $Q i \mathbb{D}^{3},{ }^{3}$ and Yang Yang $\mathbb{C}^{4}$ \\ ${ }^{1}$ Biomedical Engineering, Shanghai Jiao Tong University, Shanghai 201306, China \\ ${ }^{2}$ School of Design and Art, Shanghai Dianji University, Shanghai 201306, China \\ ${ }^{3}$ School of Business, Shanghai Dianji University, Shanghai 201306, China \\ ${ }^{4}$ Mechanics Institute, Shanghai Dianji University, Shanghai 201306, China
}

Correspondence should be addressed to Zhi-yong Zhou; zhouzhiyong001@126.com

Received 21 February 2021; Accepted 28 April 2021; Published 12 May 2021

Academic Editor: Xinguang Zhang

Copyright ( 2021 Zhi-yong Zhou et al. This is an open access article distributed under the Creative Commons Attribution License, which permits unrestricted use, distribution, and reproduction in any medium, provided the original work is properly cited.

\begin{abstract}
In view of the lack of objective data support for product evaluation methods in the industry, a triangular verification method was proposed; it considered nursing beds as the study object and combined subjective evaluation with eye movement and electroencephalogram. Because the triangular validation method is based on the numerical value between the indicators and the frequency of ranking, this method is worth investigating for analyzing experimental data more scientifically. This paper focuses on the further analysis of the experimental data, especially the use of interval estimation method. After analysis, we obtain that proposal 2 is the optimal solution. This method is more suitable for product evaluation which will collect large amount of experimental data to obtain more accurate results. For industrial product designers, the evaluation of products by users is very important. In the design stage, how to grasp the user's evaluation of the product more accurately is a difficult problem. This paper takes nursing bed as the research object and studies the user participation design in order to make the product more acceptable to most people after it is launched.
\end{abstract}

\section{Introduction}

Nursing beds are designed as original ordinary steel beds, mechanical transmission beds, electric beds, or multifunctional beds. With the development of computer technology, development of multifunctional nursing beds is increasing. The development of multifunctional nursing beds is a breakthrough in realizing comprehensive nursing and is also an innovation in patient healthcare function [1]. With the development of information network, sensor, intelligent control, and bionic technology as well as the intersection of electromechanical technology and biotechnology, the development direction of multifunctional nursing bed is networking, digitalization, and intellectualization $[2,3]$. The higher the level of medical treatment, the greater the pursuit of living standards and quality. Users not only require basic functions, safety, and practicality of the product but also pay more attention to comfort, aesthetics, and emotion of the product $[4,5]$. However, the design of medical beds is obviously lacking in terms of Kansei engineering [6,7]. As a result, patients not only suffer from illnesses but also feel inconvenienced due to unreasonable designs [8]. It is extremely important to improve and promote the design of medical beds for patients. In recent years, most studies on nursing beds focus on function and user experience. The research on function focuses on solving problems of patients and nurses when using nursing beds. For example, Enoi et al. [9] designed a smart bed to help nurses move overweight patients slowly and smoothly from the bed to other places. In addition, Takanokura et al. developed a systematic approach to use sensors around the nursing bed to prevent falls and secondary injuries.

The evaluation of nursing beds also focuses on functionality. Boorman et al. [10] assessed the value of a "Clinitron" air-fluidized bed in the setting of a general 


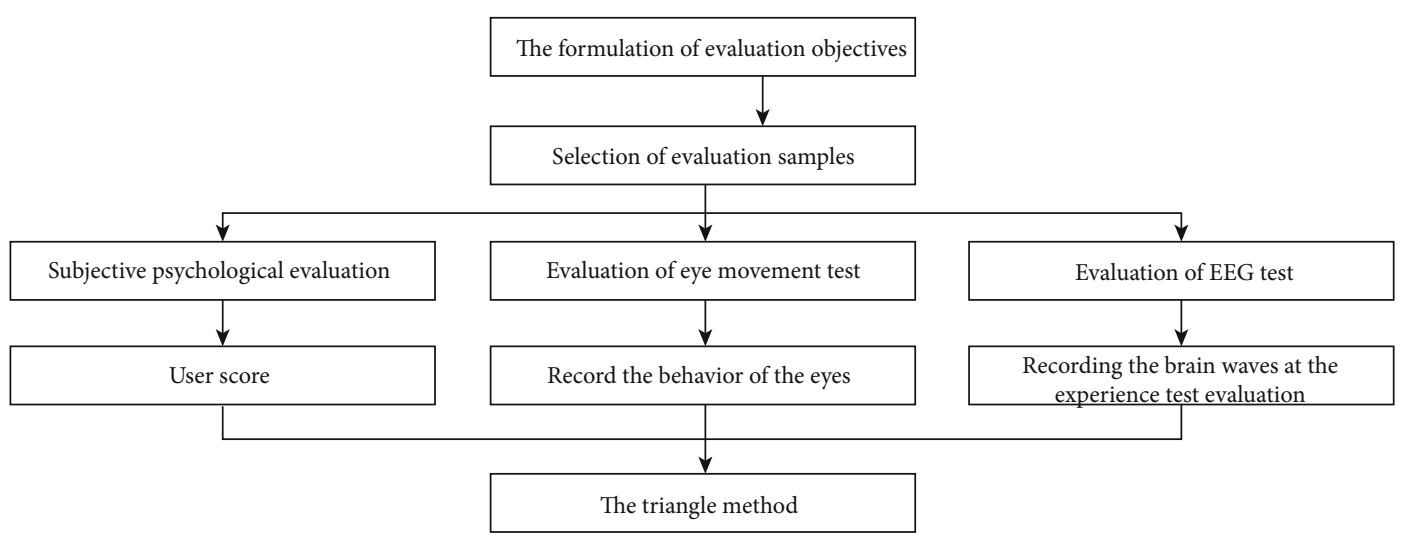

FIGURE 1: Experimental process of the triangular verification model.

plastic surgery unit by using pressure sensor data in 1981 . Milward et al. [11] put forward the Walsall scoring system, which was designed with community patients in mind; it was later improved by Chaloner and Franks [12]. A scoring system is typically used to evaluate the medical system for both hospital and community staff. Some researchers pay more attention to decompressing equipment such as the mattress of the nursing bed, which can also be called a pressure-reducing foam mattress (PRFM); they evaluated the role of PRFMs [13-15]. They also focused on the evaluation of long-term clinical efficacy of PRFMs and found that PRFMs perform well after 3 and 4 years, respectively, in two different clinics [16]. In 2016, Gray et al. not just evaluated PRFMs but also electric bed frames [17]. All these studies focus on the functionality of equipment and the extent to which it can reduce the physical workload of nurses and improve the dignity and comfort of patients.

In terms of a product evaluation system, the current evaluation method is mainly based on expert opinions combined with random sampling. Subjective factors are major contributors in this evaluation method; it is impossible to determine whether the obtained evaluation is a true evaluation. Therefore, in a previous article, a triangular verification method, by combining subjective evaluation, electroencephalogram (EEG) data, and eye movement data, was proposed for a more convincing evaluation method [18].

Based on Kansei engineering [19], the psychological and physiological data collected from the experiment were combined, i.e., subjective evaluation, eye movement, and EEG data; a triangular validation system of nursing bed, which is based on the fact that there is correlation between subjective evaluation, eye movement, and EEG data, was established. The specific execution process is shown in Figure 1.

In Figure 1, we first identify the purpose of the evaluation, which is proposing four nursing bed designs. Participants were selected, and the Likert scale method [20] was used to obtain the subjective evaluation, eye movement, and EEG data synchronously using an instrument. Finally, the four proposals were ranked in terms of subjective evaluation, eye movement data, and EEG data; the final results were verified to improve the reliability of subjective evaluation. The four proposed nursing beds are marked as $\mathrm{C} 1, \mathrm{C} 2, \mathrm{C} 3$, and $\mathrm{C} 4$ as shown in Figure 2.

The experimental method is shown in Figure 3. Tobii X3-120 [21], a small eye movement tracking instrument developed by Sweden Tobii Company, was used in the experiment; its accuracy is 0.2 degrees and the sampling rate is $120 \mathrm{~Hz}$. It can provide portability and large head movement range and ensure high-quality tracking accuracy and stable tracking. The EEG signal acquisition instrument used in the experiment was NeurOne innovative research system produced by Mega Electronics, USA. It has 24-bit analog-to-digital conversion with sensitivity of $51 \mathrm{nV} / \mathrm{bit}$ and input range of $+430 \mathrm{mV}$, and the 40 channel amplifier includes $32 \mathrm{EEG}+8$ bipolar channels. This neuroscience measurement system provides a more accurate and cleaner signal, faster sampling, modular solutions, use of the latest processing in digital signal processing, more flexibility, and scalability.

Data were obtained from 20 participants with normal vision. All the data in this experiment were obtained according to relevant standards. The experimental process is as follows:

(1) Participants washed their hair with shampoo and dried it

(2) Participants watched and understood the experimental guidance and signed the statement

(3) Researchers prepared experimental instruments

(4) Researchers explained the experimental process to the participants

(5) At the beginning of the experiment, participants looked at the first randomly occurring proposal of the medical nursing bed and scored by pressing a button from 1 to 5 (1-worst; 2-worse; 3-normal; 4-better; 5-best). When the participants press the button, the first rendering experiment ends and the second rendering experiment begins until all the experimental materials are completed. To ensure the effectiveness of the experiment, after the first round of grading, four proposals will be 

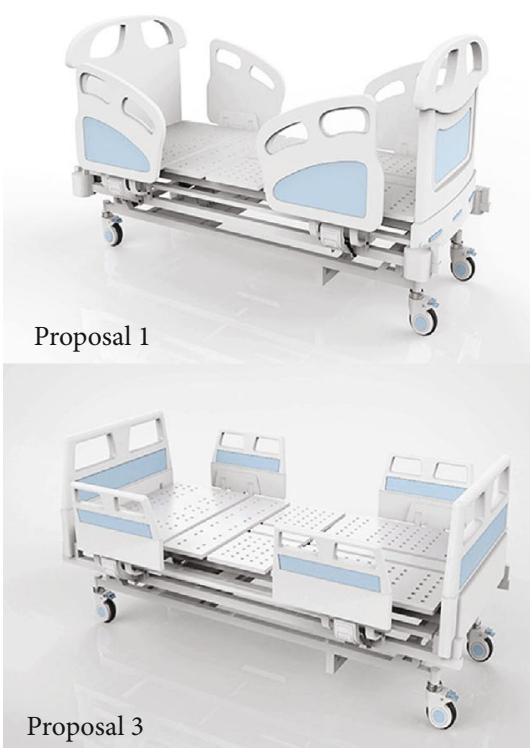

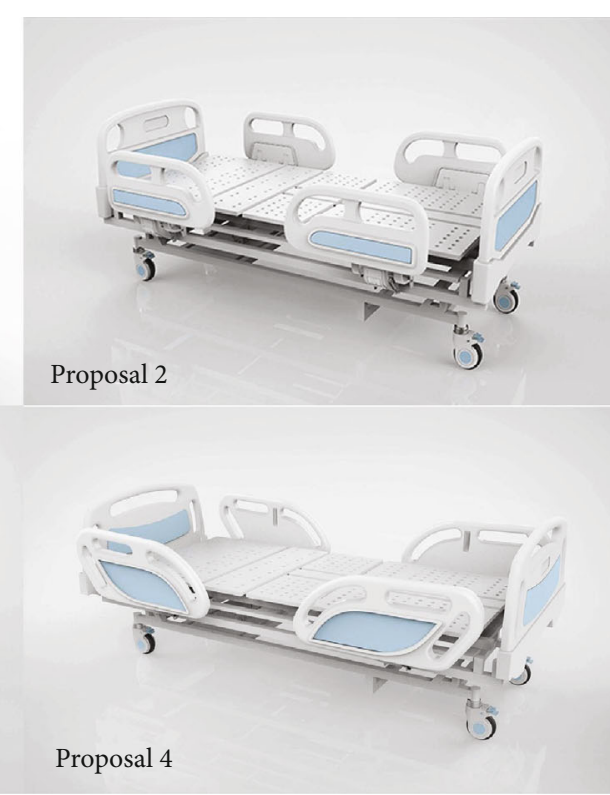

Figure 2: Four proposed nursing beds.

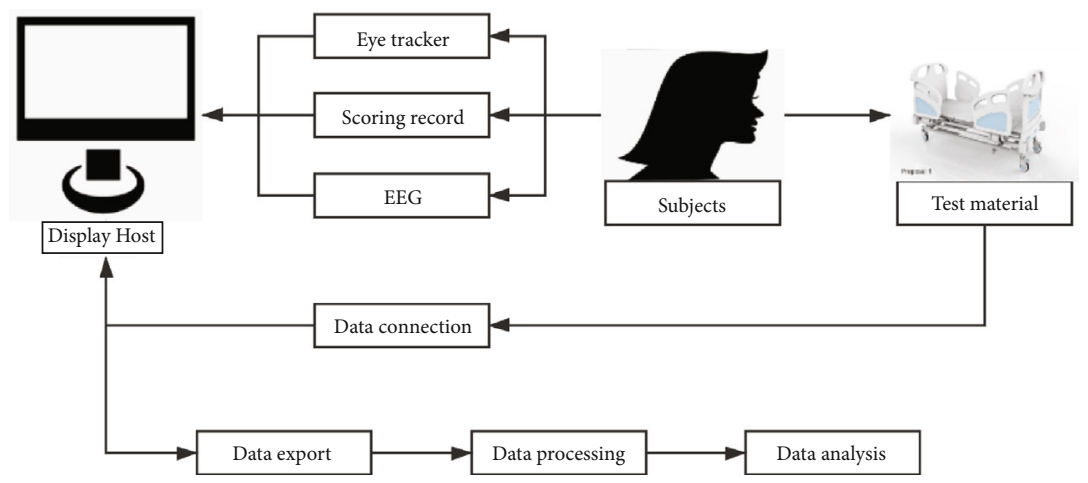

Figure 3: Experimental data acquisition model.

played randomly. The experiment was repeated 50 times

(6) After the experiment was completed, the eye tracker and brain instrument stopped recording

The experimental procedure is shown in Figure 4. data:

According to the experiment, we obtain the following

(1) The expected value of 20 people's subjective evaluation is

$$
P=\left(P_{1}, P_{2}, P_{3}, P_{4}\right)^{T} \text {. }
$$

$P_{i}$ represents the expected value of the subjective evaluation of proposal $i$ and $P_{i j}$ represents the expected value of participant $j$ 's subjective evaluation of proposal $i$; the calcula- tion process is as follows:

$$
P_{i}=\frac{1}{20} \sum_{j=1}^{20} P_{i j}(1 \leq i \leq 4 ; 1 \leq j \leq 20),
$$$$
P_{i j}=\frac{1}{50} \sum_{n=1}^{50} P_{i j n}(1 \leq i \leq 4 ; 1 \leq j \leq 20 ; 1 \leq n \leq 50) \text {. }
$$

(2) The expected value of 20 people's eye movement data is

$$
E=\left(\begin{array}{lll}
E_{11} & E_{12} & E_{13} \\
E_{21} & E_{22} & E_{23} \\
E_{31} & E_{32} & E_{33} \\
E_{41} & E_{42} & E_{43}
\end{array}\right) .
$$




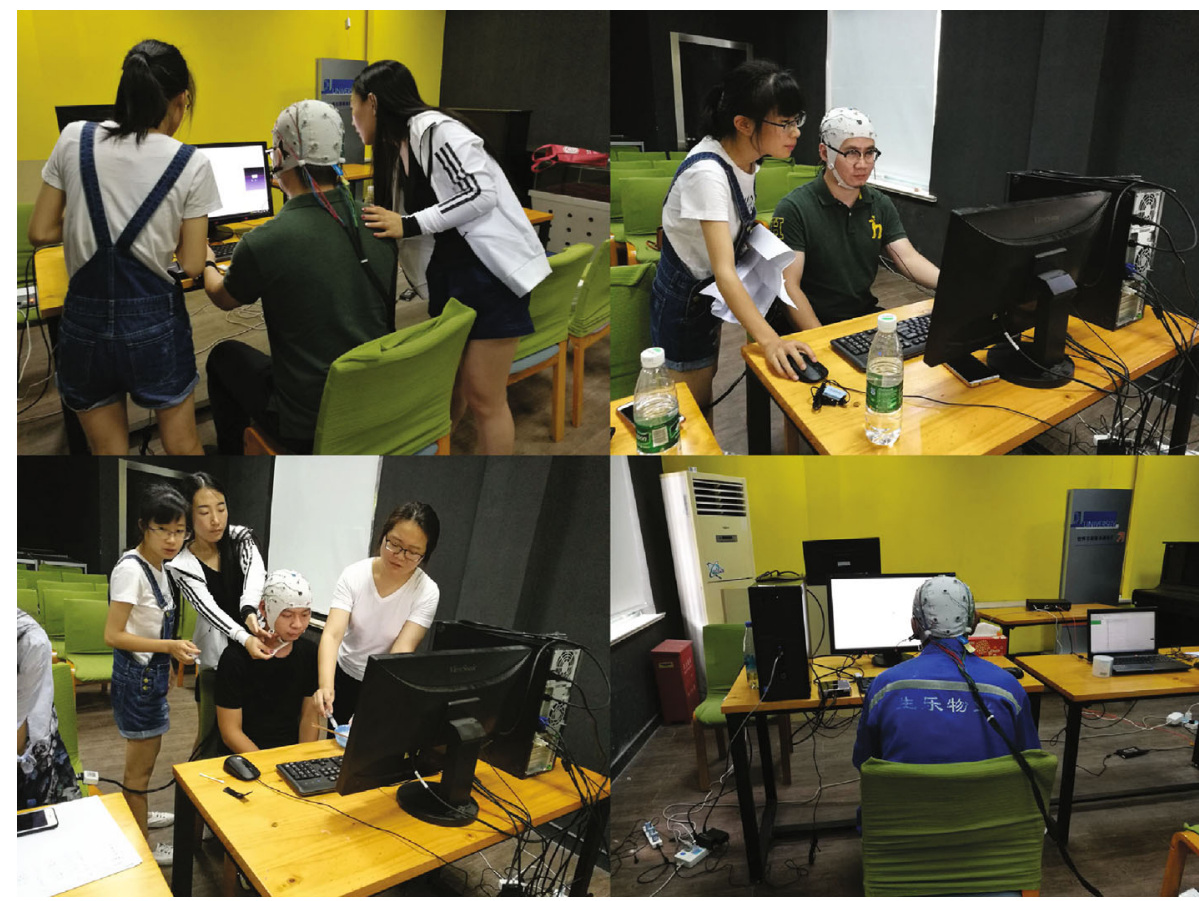

FIgURE 4: Experimental setup.

32 ch BC-32-X22 epochs pruned with ICA

$$
\text { }
$$

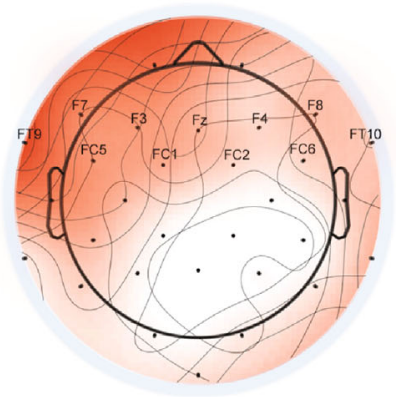

FIGURE 5: Electrode and topographic map.

$E_{i 1}$ represents the expected value of the fixation time for proposal $i(i=1,2,3,4)$ marked as e1. $E_{i 2}$ represents the expected value of the number of fixations for proposal $i$ $(i=1,2,3,4)$ marked as e2. $E_{i 3}$ represents the expected value of the first fixation time for proposal $i$ $(i=1,2,3,4)$ marked as $\mathrm{e} 3$; the calculation process is as follows:

$$
\begin{gathered}
E_{i j}=\frac{1}{20} \sum_{k=1}^{20} E_{i j k}(1 \leq i \leq 4 ; 1 \leq j \leq 3 ; 1 \leq k \leq 20), \\
E_{i j k}=\frac{1}{50} \sum_{n=1}^{50} E_{i j k n}(1 \leq i \leq 4 ; 1 \leq j \leq 3 ; 1 \leq k \leq 20 ; 1 \leq n \leq 50) .
\end{gathered}
$$

(3) The expected value of 20 people's EEG data is

$$
D=\left(\begin{array}{cccc}
D_{11} & D_{12} & \cdots & D_{1 j} \\
D_{21} & D_{22} & \cdots & D_{2 j} \\
D_{31} & D_{32} & \cdots & D_{3 j} \\
D_{41} & D_{42} & \cdots & D_{4 j}
\end{array}\right) .
$$

$D_{i j}$ represents the expected value of index $j$ of EEG data for proposal $i(i=1,2,3,4)$. In this experiment, the observed electrodes and overlapping topographic maps are shown in Figure 5. According to the brain topographic map, 11 electrodes were selected in the most active area, named F4, F7, F8, FZ, FC1, FC2, FC5, FC6, ft9, ft10, and F3; therefore, in 
this experiment, $1 \leq j \leq 11$.

$$
\begin{gathered}
D_{i j}=\frac{1}{20} \sum_{k=1}^{20} D_{i j k}(1 \leq i \leq 4 ; 1 \leq j \leq 3 ; 1 \leq k \leq 20), \\
D_{i j k}=\frac{1}{50} \sum_{n=1}^{50} D_{i j k n}(1 \leq i \leq 4 ; 1 \leq j \leq 3 ; 1 \leq k \leq 20 ; 1 \leq n \leq 50) .
\end{gathered}
$$

Based on the above analysis, we can obtain matrix $Z$ as follows:

The final data obtained are as follows:

$$
Z=\left(\begin{array}{ccccccccccccccc}
3.65 & 1.86 & 6.69 & 1.28 & 2.46 & 2.9 & 2.67 & 3.56 & 2.45 & 4.11 & 1.74 & 3.15 & 1.67 & 6.04 & 3.97 \\
3.76 & 2 & 7.88 & 1.21 & 3.08 & 2.97 & 3.1 & 4.09 & 3.43 & 4.76 & 1.99 & 3.31 & 2.11 & 6.32 & 4.94 \\
3.07 & 1.75 & 6.33 & 1.54 & 1.69 & 2.64 & 2.37 & 2.63 & 2.27 & 3.76 & 1.39 & 2.48 & 1.39 & 5.4 & 3.31 \\
3.45 & 1.85 & 6.11 & 1.37 & 2.01 & 2.74 & 2.51 & 3.01 & 2.55 & 3.73 & 1.36 & 2.43 & 1.61 & 5.47 & 3.49
\end{array}\right.
$$

The correlation analysis of the data is carried out, and the results are shown in Tables 1-3.

It can be seen from the table that there is a certain correlation between subjective evaluation data, eye movement data, and EEG data. The first fixation time was negatively correlated with other indicators because the shorter the first fixation time, the more attention the participants paid, and vice versa.

Then, we need to analyze the results in terms of three different factors, namely, subjective evaluation, eye movement, and EEG data. First, proximity analysis is carried out.

Procedure 1. To calculate the maximum $F_{i j}^{+}$and minimum $F_{i j}^{-}$ of each evaluation index.

$$
\begin{aligned}
& F_{i j}^{+}=\max \left\{Z_{i j}\right\}(1 \leq i \leq 4 ; 1 \leq j \leq 15), \\
& F_{i j}^{-}=\min \left\{Z_{i j}\right\}(1 \leq i \leq 4 ; 1 \leq j \leq 15) .
\end{aligned}
$$

Procedure 2. To calculate the distance from the maximum to minimum of each proposal.

$$
\begin{aligned}
& d_{i j}^{+}=F_{i j}^{+}-Z_{i j}(1 \leq i \leq 4 ; 1 \leq j \leq 15), \\
& d_{i j}^{-}=Z_{i j}-F_{i j}^{+}(1 \leq i \leq 4 ; 1 \leq j \leq 15) .
\end{aligned}
$$

Procedure 3. To calculate relative closeness of evaluative value and maximum value for each program.

We use the relative closeness of evaluative value and maximum value for each proposal as the foundation of the final evaluation for the design proposal.

$$
Z_{i j}^{\prime}=\frac{d_{i j}^{-}}{d_{i j}^{-}+d_{i j}^{+}} .
$$

Through the above steps, we can obtain the results of the close degree analysis data as shown in Table 4. Because the first fixation time is negatively related to other indicators, the smaller the value, the closer will be the ranking.

Then, we use the frequency statistics method for the three factors and obtain the final ranking method according to the frequency of the four rankings. The specific calculation formula is as follows:

$$
f_{i p}=\frac{R_{i p}}{Z_{b}} .
$$

The frequency of proposal $i$ appearing in the $P$ ranking is the number of effective evaluation indexes in different dimensions. In this paper, in the subjective evaluation dimension $Z_{b}=1$, in the eye movement evaluation dimension $Z_{b}=3$, and in the EEG evaluation dimension $Z_{b}=11$; $f_{i} p$ is the frequency of proposal $i$ appearing in the $P$ ranking. The specific frequency of the four proposals under different dimensions and ranking is shown in Tables 5-7.

From Tables 5-7, we can see that from the perspective of subjective evaluation, the ranking is $\mathrm{C} 2>\mathrm{C} 1>\mathrm{C} 3>\mathrm{C} 4$; from the perspective of eye movement data, the ranking is $\mathrm{C} 2>\mathrm{C} 1>\mathrm{C} 4>\mathrm{C} 3$; from the perspective of the EEG evaluation data, the ranking is $\mathrm{C} 2>\mathrm{C} 1>\mathrm{C} 4>\mathrm{C} 3$. We can see that from the three dimensions, which are subjective valuation, eye movement data, and EEG objective data to evaluate the four proposals, sorting results are the same. The triangular validation was passed, indicating that the experimental subject evaluation is highly reliable.

Because the original triangular validation method mainly relies on the size of the data value to arrange the data, which is not convincing to a certain extent, there is contingency; therefore, this study focuses on data processing, especially of the confidence interval validation method used in data 
TABLE 1: Correlation analysis data 1.

\begin{tabular}{lcccccccc}
\hline & $P$ & e1 & e2 & e3 & F4 & F7 & F8 & FZ \\
\hline$P$ & 1 & 0.903 & 0.693 & -0.998 & 0.919 & 0.966 & 0.862 & 0.944 \\
e1 & 0.903 & 1 & 0.866 & -0.926 & 0.963 & 0.903 & 0.973 & 0.949 \\
e2 & 0.693 & 0.866 & 1 & -0.731 & 0.921 & 0.822 & 0.954 & 0.890 \\
e3 & -0.998 & -0.926 & -0.731 & 1 & -0.939 & -0.973 & -0.890 & -0.959 \\
F4 & 0.919 & 0.963 & 0.921 & -0.939 & 1 & 0.97 & 0.988 & 0.996 \\
F7 & 0.966 & 0.903 & 0.822 & -0.973 & 0.97 & 1 & 0.921 & 0.988 \\
F8 & 0.862 & 0.973 & 0.954 & -0.89 & 0.988 & 0.921 & 1 & 0.970 \\
FZ & 0.944 & 0.949 & 0.890 & -0.959 & 0.996 & 0.988 & 0.970 & 1 \\
\hline
\end{tabular}

TABLE 2: Correlation analysis data 2.

\begin{tabular}{lcccccccc}
\hline & $P$ & e1 & e2 & e3 & F4 & F7 & F8 & FZ \\
\hline FC1 & 0.729 & 0.951 & 0.914 & -0.767 & 0.895 & 0.767 & 0.951 & 0.855 \\
FC2 & 0.773 & 0.905 & 0.993 & -0.806 & 0.960 & 0.883 & 0.979 & 0.938 \\
FC5 & 0.825 & 0.859 & 0.946 & -0.847 & 0.962 & 0.940 & 0.944 & 0.959 \\
FC6 & 0.835 & 0.784 & 0.865 & -0.847 & 0.922 & 0.948 & 0.875 & 0.936 \\
FT9 & 0.872 & 0.994 & 0.915 & -0.899 & 0.972 & 0.898 & 0.990 & 0.952 \\
FT10 & 0.887 & 0.872 & 0.902 & -0.903 & 0.971 & 0.976 & 0.937 & 0.979 \\
F3 & 0.838 & 0.951 & 0.973 & -0.867 & 0.985 & 0.917 & 0.996 & 0.966 \\
\hline
\end{tabular}

TABLE 3: Correlation analysis data 3.

\begin{tabular}{lccccccc}
\hline & FC1 & FC2 & FC5 & FC6 & FT9 & FT10 & F3 \\
\hline FC1 & 1 & 0.917 & 0.81 & 0.687 & 0.969 & 0.784 & 0.937 \\
FC2 & 0.917 & 1 & 0.971 & 0.904 & 0.943 & 0.943 & 0.992 \\
FC5 & 0.81 & 0.971 & 1 & 0.98 & 0.891 & 0.991 & 0.964 \\
FC6 & 0.687 & 0.904 & 0.98 & 1 & 0.81 & 0.987 & 0.898 \\
FT9 & 0.969 & 0.943 & 0.891 & 0.81 & 1 & 0.891 & 0.975 \\
FT10 & 0.784 & 0.943 & 0.991 & 0.987 & 0.891 & 1 & 0.95 \\
F3 & 0.937 & 0.992 & 0.964 & 0.898 & 0.975 & 0.95 & 1 \\
\hline
\end{tabular}

TABLE 4: Data table for proximity analysis.

\begin{tabular}{lccccc}
\hline Index & C1 & C2 & C3 & C4 & Proposal sorting \\
\hline$P$ & 0.84 & 1 & 0 & 0.55 & $\mathrm{C} 2>\mathrm{C} 1>\mathrm{C} 4>\mathrm{C} 3$ \\
e1 & 0.44 & 1 & 0 & 0.4 & $\mathrm{C} 2>\mathrm{C} 1>\mathrm{C} 4>\mathrm{C} 3$ \\
e2 & 0.33 & 1 & 0.12 & 0 & $\mathrm{C} 2>\mathrm{C} 1>\mathrm{C} 3>\mathrm{C} 4$ \\
e3 & 0.21 & 0 & 1 & 0.48 & $\mathrm{C} 2>\mathrm{C} 1>\mathrm{C} 4>\mathrm{C} 3 *$ \\
F4 & 0.55 & 1 & 0 & 0.23 & $\mathrm{C} 2>\mathrm{C} 1>\mathrm{C} 4>\mathrm{C} 3$ \\
F7 & 0.79 & 1 & 0 & 0.3 & $\mathrm{C} 2>\mathrm{C} 1>\mathrm{C} 4>\mathrm{C} 3$ \\
F8 & 0.41 & 1 & 0 & 0.19 & $\mathrm{C} 2>\mathrm{C} 1>\mathrm{C} 4>\mathrm{C} 3$ \\
FZ & 0.64 & 1 & 0 & 0.26 & $\mathrm{C} 2>\mathrm{C} 1>\mathrm{C} 4>\mathrm{C} 3$ \\
FC1 & 0.16 & 1 & 0 & 0.24 & $\mathrm{C} 2>\mathrm{C} 4>\mathrm{C} 1>\mathrm{C} 3$ \\
FC2 & 0.37 & 1 & 0.03 & 0 & $\mathrm{C} 2>\mathrm{C} 1>\mathrm{C} 3>\mathrm{C} 4$ \\
FC5 & 0.6 & 1 & 0.05 & 0 & $\mathrm{C} 2>\mathrm{C} 1>\mathrm{C} 3>\mathrm{C} 4$ \\
FC6 & 0.82 & 1 & 0.06 & 0 & $\mathrm{C} 2>\mathrm{C} 1>\mathrm{C} 3>\mathrm{C} 4$ \\
FT9 & 0.39 & 1 & 0 & 0.31 & $\mathrm{C} 2>\mathrm{C} 1>\mathrm{C} 4>\mathrm{C} 3$ \\
FT10 & 0.7 & 1 & 0 & 0.08 & $\mathrm{C} 2>\mathrm{C} 1>\mathrm{C} 4>\mathrm{C} 3$ \\
F3 & 0.4 & 1 & 0 & 0.11 & $\mathrm{C} 2>\mathrm{C} 1>\mathrm{C} 4>\mathrm{C} 3$ \\
\hline
\end{tabular}

TABLE 5: Frequency table of subjective evaluation.

\begin{tabular}{|c|c|c|c|c|c|c|c|c|}
\hline \multirow[t]{2}{*}{$\begin{array}{l}\text { Subjective evaluation } \\
\text { proposal ranking }\end{array}$} & \multicolumn{2}{|c|}{$\begin{array}{l}\text { First } \\
\text { place }\end{array}$} & \multicolumn{2}{|c|}{$\begin{array}{l}\text { Second } \\
\text { place }\end{array}$} & \multicolumn{2}{|c|}{$\begin{array}{l}\text { Third } \\
\text { place }\end{array}$} & \multicolumn{2}{|c|}{$\begin{array}{c}\text { Fourth } \\
\text { place }\end{array}$} \\
\hline & $R_{i p}$ & $f_{i p}$ & $R_{i p}$ & $f_{i p}$ & $R_{i p}$ & $f_{i p}$ & $R_{i p}$ & $f_{i p}$ \\
\hline $\mathrm{C} 1$ & 0 & 0.00 & 1 & 1.00 & 0 & 0.00 & 0 & 0.00 \\
\hline $\mathrm{C} 2$ & 1 & 1.00 & 0 & 0.00 & 0 & 0.00 & 0 & 0.00 \\
\hline $\mathrm{C} 3$ & 0 & 0.00 & 0 & 0.00 & 0 & 0.00 & 1 & 1.00 \\
\hline $\mathrm{C} 4$ & 0 & 0.00 & 0 & 0.00 & 1 & 1.00 & 0 & 0.00 \\
\hline Final ranking & \multicolumn{2}{|c|}{ C2 } & \multicolumn{2}{|c|}{$\mathrm{C} 1$} & \multicolumn{2}{|c|}{ C4 } & \multicolumn{2}{|c|}{ C3 } \\
\hline
\end{tabular}

TABLE 6: Frequency table of eye movement test evaluation.

\begin{tabular}{lccccccccc}
\hline Subjective evaluation & \multicolumn{2}{c}{$\begin{array}{c}\text { First } \\
\text { proposal ranking }\end{array}$} & \multicolumn{3}{c}{$\begin{array}{c}\text { Second } \\
\text { place }\end{array}$} & \multicolumn{3}{c}{ Third } & \multicolumn{2}{c}{$\begin{array}{c}\text { Fourth } \\
\text { place }\end{array}$} & \multicolumn{3}{c}{ place } \\
& $R_{i p}$ & $f_{i p}$ & $R_{i p}$ & $f_{i p}$ & $R_{i p}$ & $f_{i p}$ & $R_{i p}$ & $f_{i p}$ \\
\hline C1 & 0 & 0.00 & 3 & 1.00 & 0 & 0.00 & 0 & 0.00 \\
C2 & 3 & 1.00 & 0 & 0.00 & 0 & 0.00 & 0 & 0.00 \\
C3 & 0 & 0.00 & 0 & 0.00 & 1 & 0.33 & 2 & 0.67 \\
C4 & 0 & 0.00 & 0 & 0.00 & 2 & 0.67 & 1 & 0.33 \\
Final ranking & $\mathrm{C} 2$ & $\mathrm{C} 1$ & $\mathrm{C} 4$ & $\mathrm{C} 3$ \\
\hline
\end{tabular}

TABLE 7: Frequency table of EEG test evaluation.

\begin{tabular}{|c|c|c|c|c|c|c|c|c|}
\hline \multirow[t]{2}{*}{$\begin{array}{l}\text { Subjective evaluation } \\
\text { proposal ranking }\end{array}$} & \multicolumn{2}{|c|}{$\begin{array}{l}\text { First } \\
\text { place }\end{array}$} & \multicolumn{2}{|c|}{$\begin{array}{l}\text { Second } \\
\text { place }\end{array}$} & \multicolumn{2}{|c|}{$\begin{array}{l}\text { Third } \\
\text { place }\end{array}$} & \multicolumn{2}{|c|}{$\begin{array}{l}\text { Fourth } \\
\text { place }\end{array}$} \\
\hline & $R_{i p}$ & $f_{i p}$ & $R_{i p}$ & $f_{i p}$ & $R_{i p}$ & $f_{i p}$ & $R_{i p}$ & $f_{i p}$ \\
\hline$\overline{\mathrm{C} 1}$ & 0 & 0.00 & 10 & 0.91 & 1 & 0.09 & 0 & 0.00 \\
\hline $\mathrm{C} 2$ & 11 & 1.00 & 0 & 0.00 & 0 & 0.00 & 0 & 0.00 \\
\hline $\mathrm{C} 3$ & 0 & 0.00 & 0 & 0.00 & 3 & 0.27 & 8 & 0.73 \\
\hline $\mathrm{C} 4$ & 0 & 0.00 & 1 & 0.09 & 7 & 0.64 & 3 & 0.27 \\
\hline Final ranking & \multicolumn{2}{|c|}{$\mathrm{C} 2$} & \multicolumn{2}{|c|}{$\mathrm{C} 1$} & \multicolumn{2}{|c|}{$\mathrm{C} 4$} & \multicolumn{2}{|c|}{$\mathrm{C} 3$} \\
\hline
\end{tabular}

analysis. We assume that the reader is familiar with the basic notions of statistical theory.

\section{Methods}

According to central limit theorem [22], for independent random variables, when the number is large, the data distribution follows a normal distribution. Then, according to the correlation and significance between the fifteen indicators of this experiment, F3 was selected as the specific analysis index.

The specific data of proposal 1 of the F3 indicator are as follows: $\quad F 3-1=(2.8423 .4060 .9960 .8063 .5802 .2567 .515$ 0.4350 .9431 .1650 .9910 .8243 .6161 .1581 .5869 .1911 .447 $3.1891 .9141 .321)$.

The box diagram of the F3 index is shown in Figure 6. Because the experimental data of participant 7 and participant 16 deviated too much from other data, the data of these two individuals was rejected [23].

The final data and sample size $n$, sample mean $\bar{X}$, sample standard deviation $S$, and sample variance $S^{2}$ are shown in Table 8. 


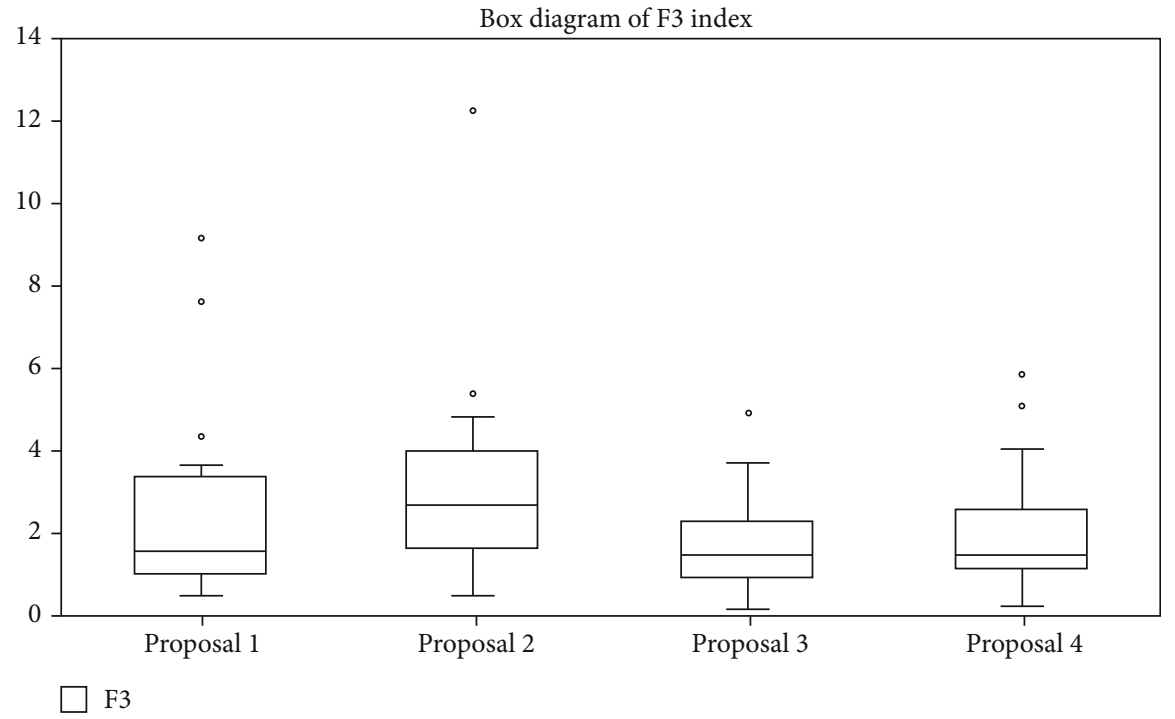

FIgURE 6: Box diagram of the F3 index.

TABle 8: F3 index data sheet.

\begin{tabular}{|c|c|c|c|c|}
\hline Participant & F3-1 & F3-2 & F3-3 & F3-4 \\
\hline 1 & 2.842 & 3.203 & 4.900 & 5.187 \\
\hline 2 & 3.406 & 2.500 & 1.314 & 1.233 \\
\hline 3 & 0.996 & 4.231 & 0.898 & 3.546 \\
\hline 4 & 0.806 & 0.514 & 0.095 & 0.174 \\
\hline 5 & 3.580 & 1.805 & 1.460 & 1.341 \\
\hline 6 & 2.256 & 1.989 & 1.284 & 2.605 \\
\hline 8 & 0.435 & 0.674 & 0.457 & 0.875 \\
\hline 9 & 0.943 & 3.273 & 1.867 & 3.999 \\
\hline 10 & 1.165 & 2.203 & 1.410 & 1.482 \\
\hline 11 & 0.991 & 1.385 & 0.568 & 0.438 \\
\hline 12 & 0.824 & 2.206 & 2.159 & 1.108 \\
\hline 13 & 3.616 & 4.230 & 2.686 & 1.148 \\
\hline 14 & 1.158 & 1.287 & 0.722 & 1.596 \\
\hline 15 & 1.586 & 4.807 & 2.457 & 1.241 \\
\hline 17 & 1.447 & 3.501 & 1.076 & 0.881 \\
\hline 18 & 3.189 & 2.851 & 2.219 & 1.999 \\
\hline 19 & 1.914 & 1.530 & 0.904 & 1.097 \\
\hline 20 & 1.321 & 3.301 & 1.733 & 2.500 \\
\hline$n$ & 18 & 18 & 18 & 18 \\
\hline $\bar{X}$ & 1.804 & 2.527 & 1.567 & 1.803 \\
\hline$S$ & 1.067 & 1.237 & 1.097 & 1.309 \\
\hline$S^{2}$ & 1.138 & 1.530 & 1.204 & 1.713 \\
\hline
\end{tabular}

According to Table 8, we know the specific data, sample average, and sample variance of F3- $i(i=1,2,3,4)$. According to central limit theorem [22], F3-1 to F3-4 follows normal distribution $N\left(\mu_{k}, \sigma_{k}^{2}\right)(k=1,2,3,4)$ approximately. Population average $\mu_{k}$ and population variance $\sigma_{k}^{2}(k=1,2,3,4)$ are unknown. (Formulas (13)-(15) and (17)-(20) are quoted from references [22-27].) First, we analyze F3-1 and F3-2.
TABLE 9: Variance confidence interval data in the F3 index.

\begin{tabular}{lcccccc}
\hline & $\frac{\sigma_{F 3-1}^{2}}{\sigma_{E 3-2}^{2}}$ & $\frac{\sigma_{F 3-1}^{2}}{\sigma_{F 3-3}^{2}}$ & $\frac{\sigma_{F 3-1}^{2}}{\sigma_{E 3-4}^{2}}$ & $\frac{\sigma_{F 3-2}^{2}}{\sigma_{E 3-3}^{2}}$ & $\frac{\sigma_{F 3-2}^{2}}{\sigma_{F 3-4}^{2}}$ & $\frac{\sigma_{F 3-3}^{2}}{\sigma_{E 3-4}^{2}}$ \\
\hline Lower bound & 0.393 & 0.500 & 0.351 & 0.673 & 0.473 & 0.372 \\
Upper bound & 1.405 & 1.786 & 1.255 & 2.402 & 1.688 & 1.328 \\
\hline
\end{tabular}

We need to find a confidence interval with a confidence level of 0.90 for the variance ratio $\sigma_{\mathrm{F} 3-1}^{2} / \sigma_{\mathrm{F} 3-2}^{2}$ [23]. From Table 8, we know $n_{1}=18, S_{\mathrm{F} 3-1}^{2}=1.138, n_{2}=18, S_{\mathrm{F} 3-1}^{2}=$ 1.530 , and $\alpha=0.10$.

The $F$ distribution has the following theorem:

$$
F\left(n_{1}-1, n_{2}-1\right) \sim \frac{S_{1}^{2} / S_{2}^{2}}{\sigma_{1}^{2} / \sigma_{2}^{2}}
$$

Distribution $F\left(n_{1}-1, n_{2}-1\right)$ does not depend on any unknown parameters. Taking $\left(S_{1}^{2} / S_{2}^{2}\right) /\left(\sigma_{1}^{2} / \sigma_{2}^{2}\right)$ as the pivot amount, we can obtain the following formula:

$P\left\{F_{1-\alpha / 2}\left(n_{1}-1, n_{2}-1\right)<\frac{S_{1}^{2} / S_{2}^{2}}{\sigma_{1}^{2} / \sigma_{2}^{2}}<F_{\alpha / 2}\left(n_{1}-1, n_{2}-1\right)\right\}=1-\alpha$.

Thus, we get a confidence interval of $\sigma_{1}^{2} / \sigma_{2}^{2}$ with a confidence level of $1-\alpha$ :

$$
\left(\frac{S_{1}^{2}}{S_{2}^{2}} \frac{1}{F_{\alpha / 2}\left(n_{1}-1, n_{2}-1\right)}, \frac{S_{1}^{2}}{S_{2}^{2}} \frac{1}{F_{1-\alpha / 2}\left(n_{1}-1, n_{2}-1\right)}\right) .
$$

According to the data table of $F$ distribution, we can find that $F_{0.05}(17,17)=1.89, F_{0.95}(17,17)=1 / 1.89$. According to the above formula, it can be concluded that the confidence 
TABLE 10: Confidence interval data of mean in the F3 index.

\begin{tabular}{lccccc}
\hline & $\mu_{F 3-2}-\mu_{F 3-1}$ & $\mu_{F 3-1}-\mu_{F 3-3}$ & $\mu_{F 3-1}-\mu_{F 3-4}$ & $\mu_{F 3-2}-\mu_{F 3-3}$ & $\mu_{F 3-4}-\mu_{F 3-3}$ \\
\hline Lower bound & -0.004 & -0.467 & -0.737 & 0.229 & -0.507 \\
Upper bound & 1.450 & 0.942 & 0.740 & 1.692 & 0.979 \\
\hline
\end{tabular}

TABLE 11: Confidence interval data of mean in indexes.

\begin{tabular}{lccc}
\hline & $\mu_{F 8-2}-\mu_{F 8-1}$ & $\mu_{F 8-2}-\mu_{F 8-3}$ & $\mu_{F Z-2}-\mu_{F Z-1}$ \\
Lower bound & 0.071 & 0.278 & 0.584 \\
Upper bound & 1.671 & 1.828 & 2.033 \\
& $\mu_{\mathrm{FT} 10-2}-\mu_{\mathrm{FT} 10-1}$ & $\mu_{\mathrm{FT} 10-2}-\mu_{\mathrm{FT} 10-3}$ & $\mu_{\mathrm{FT} 10-2}-\mu_{\mathrm{FT} 10-4}$ \\
Lower bound & 0.031 & 0.276 & 0.197 \\
Upper bound & 1.945 & 2.181 & 1.988 \\
\hline
\end{tabular}

interval of $\alpha=0.10$ is as follows:

$$
\left(\frac{1.138}{1.530} \times \frac{1}{1.89}, \frac{1.138}{1.530} \times 1.89\right)
$$

that is, $(0.393,1.405)$.

Because the confidence interval contains 1, we can assume that $\sigma_{F 3-1}^{2}$ and $\sigma_{F 3-2}^{2}$ are not significantly different. Similarly, we can conclude that there is no significant difference between the variance of the two proposals as shown in Table 9.

Based on the above analysis, we may consider the variance of each set of data to be equal and assume that the population variance of each data is equal. Next, we will verify the confidence interval of the population mean difference $\mu_{F 3-i}$ $-\mu_{F 3-j}(1 \leq i \neq j \leq 4)$ [28]. We take $F 3-2$ and $F 3-3$ as examples. We already know that $\bar{X}_{F 3-2} \sim N\left(\mu_{F 3-2}, \sigma_{F 3-2}^{2} /\right.$ $\left.n_{F 3-2}\right)$ and $\bar{X}_{F 3-3} \sim N\left(\mu_{F 3-3}, \sigma_{F 3-3}^{2} / n_{F 3-3}\right)$. Due to their independence, we know that

$$
\bar{X}_{F 3-2}-\bar{X}_{F 3-3} \sim N\left(\mu_{F 3-2}-\mu_{F 3-3}, \frac{\sigma_{F 3-2}^{2}}{n_{F 3-2}}+\frac{\sigma_{F 3-3}^{2}}{n_{F 3-3}}\right),
$$

or it can be written as

$$
\frac{\left(\bar{X}_{F 3-2}-\bar{X}_{F 3-3}\right)-\left(\mu_{F 3-2}-\mu_{F 3-3}\right)}{\sqrt{\left(\sigma_{F 3-2}^{2} / n_{F 3-2}\right)+\left(\sigma_{F 3-3}^{2} / n_{F 3-3}\right)}} \sim N(0,1) .
$$

A confidence level of $\bar{X}_{F 3-2}-\bar{X}_{F 3-3}$ is obtained when $\left(\bar{X}_{F 3-2}-\bar{X}_{F 3-3}\right)-\left(\mu_{F 3-2}-\mu_{F 3-3}\right) /$

$\sqrt{\left(\sigma_{F 3-2}^{2} / n_{F 3-2}\right)+\left(\sigma_{F 3-3}^{2} / n_{F 3-3}\right)}$ is chosen as a pivotal quantity, and the confidence interval of $1-\alpha$ is

$$
\left(\bar{X}_{F 3-2}-\bar{X}_{F 3-3} \pm \sqrt{\frac{\sigma_{F 3-2}^{2}}{n_{F 3-2}}+\frac{\sigma_{F 3-3}^{2}}{n_{F 3-3}}}\right)
$$

Although $\sigma_{F 3-2}^{2}$ and $\sigma_{F 3-3}^{2}$ are unknown but from for- mulas (12)-(15), we know that $\sigma_{F 3-2}^{2}=\sigma_{F 3-3}^{2}$; so we can prove that

$$
\frac{\left(\bar{X}_{F 3-2}-\bar{X}_{F 3-3}\right)-\left(\mu_{F 3-2}-\mu_{F 3-3}\right)}{S_{w} \sqrt{\left(1 / n_{F 3-2}\right)+\left(1 / n_{F 3-3}\right)}} \sim t\left(n_{F 3-2}+n_{F 3-3}-2\right) .
$$

In this formula, $S_{w}^{2}=\left(\left(n_{F 3-2}-1\right) \times S_{F 3-2}^{2}+\left(n_{F 3-3}-1\right)\right.$ $\left.\times S_{F 3-3}^{2}\right) /\left(n_{F 3-2}+n_{F 3-3}-2\right), S_{w}=\sqrt{S_{w}^{2}}$.

According to Table 8, we know that $\bar{X}_{F 3-2}=2.527$, $S_{F 3-2}=1.040$ and $\bar{X}_{F 3-3}=1.567, S_{F 3-3}=1.097$. We want to verify the confidence interval with a confidence level of 0.95 for the two population mean difference $\mu_{F 3-2}-\mu_{F 3-3}$. We know $1-\alpha=0.95, \alpha / 2=0.025, n_{2}=18, n_{3}=18, n_{2}+n_{3}-2$ $=34, t_{0.025}(34)=2.0322, S_{w}^{2}=(17 \times 2.527+17 \times 1.567) / 34$, and $S_{w}=\sqrt{S_{w}^{2}}=1.0803$.

Based on the above formulas, we can obtain the confidence intervals as

$$
\left(\bar{X}_{F 3-2}-\bar{X}_{F 3-3} \pm S_{w} \times t_{0.025}(34) \sqrt{\frac{1}{18}+\frac{1}{18}}\right)=(0.960 \pm 0.732),
$$

that is, $(0.229,1.189)$.

Because the lower bound of the confidence interval is greater than zero, $\mu_{\mathrm{F} 3-2}$ can be considered to be greater than $\mu_{F 3-3}$. Thus, we can infer that according to the F3 index, proposal 2 is better than proposal 3. Similarly, other results are shown in Table 10.

Similarly, in proposal 3, proposal 1, and proposal 4, the lower bound of confidence interval is lower than zero; therefore, we can conclude that according to the F3 index in this analysis method, there is no significant difference between proposal 3, proposal 1, and proposal 4. 


\section{Results}

The same analysis method was adopted to verify the other 14 indexes; the nine indicators cannot draw a clear conclusion. Specific conclusions are shown in Table 11. According to the F8 index and FZ index, we can conclude that proposal 2 is better than proposal 1 , and proposal 2 is better than proposal 3. According to the FT10 index, we can conclude that proposal 2 is better than proposal 1, proposal 3, and proposal 4.

According to the data obtained, we can see that proposal 2 is better than the others, that is, proposal 2 is the best, which is consistent with the previous conclusion.

\section{Conclusions}

In this study, we improved the way of data comparison in the triangular validation method. We apply the confidence interval in statistics to the analysis model and improve the problem of previous data comparison which is being too simple. Because less amount of data is collected in this experiment, a definite result cannot be acquired from a single indicator. However, according to statistical theory, when the number of data sample is large, the model constructed will draw a clear conclusion. This study shows that mathematical statistics can be well used in product evaluation and that triangular evaluation is deepened to make the evaluation model more convincing and applicable. With the development of intelligent wearable equipment, data acquisition will become more convenient in the future. Therefore, this evaluation model should have an extensive application and research value. We hope that more mathematical and statistical knowledge will be used for product evaluation to promote the development of industrial evaluation systems. Next, we will analyze the product evaluation in industrial design and guide the product design process through the analysis of a large number of data.

\section{Data Availability}

No data were used to support this study.

\section{Conflicts of Interest}

The authors declare that they have no conflicts of interest.

\section{Acknowledgments}

The work presented in this paper is supported by Shanghai Multidirection Die Forging Engineering Technology Research Center (No. 20DZ2253200), National Key R\&D Program-Research on Modernization of Traditional Chinese Medicine (2018YFC1707802), and science and technology support project in biomedical field of "Science and Technology Innovation Action Plan" of Shanghai in 2019 (No. 19441914900).

\section{References}

[1] N. Sakamoto, "The construction of a public key infrastructure for healthcare information networks in Japan," Studies in Health Technology And Informatics, vol. 84, article 1276, Part 2, 2001.

[2] J. Demmer, A. Kitzig, G. Stockmanns, E. Naroska, R. Viga, and A. Grabmaier, Adaptation of Cluster Analysis Methods to Optimize a Biomechanical Motion Model of Humans in a Nursing Bed [C]// EUSIPCO 2020, 2020.

[3] L. Wei and L. Li, "Multi-functional nursing bed lateral function improvement design," Journal of Physics: Conference Series, vol. 1601, no. 5, article 052023, p. 5, 2020.

[4] M. M. Gelici-Zeko, D. Lutters, R. ten Klooster, and P. L. Weijzen, "Studying the influence of packaging design on consumer perceptions (of dairy products) using categorizing and perceptual mapping," Packaging Technology and Science, vol. 26, no. 4, pp. 215-228, 2013.

[5] T. Nanda, B. Sahoo, H. Beria, and C. Chatterjee, "A waveletbased non-linear autoregressive with exogenous inputs (WNARX) dynamic neural network model for real-time flood forecasting using satellite-based rainfall products," Journal of Hydrology, vol. 539, pp. 57-73, 2016.

[6] R. K. Mohanty, R. C. Mohanty, and S. K. Sabut, "A systematic review on design technology and application of polycentric prosthetic knee in amputee rehabilitation," Physical and Engineering Sciences in Medicine, vol. 43, no. 3, pp. 781-798, 2020.

[7] G. T. Jun, A. Canham, A. Altuna-Palacios et al., "A participatory systems approach to design for safer integrated medicine management," Ergonomics, vol. 61, no. 1, pp. 48-68, 2018.

[8] O. E. Agwu, J. U. Akpabio, S. B. Alabi, and A. Dosunmu, "Artificial intelligence techniques and their applications in drilling fluid engineering: a review," Journal of Petroleum Science and Engineering, vol. 167, pp. 300-315, 2018.

[9] S. A. L. Enoi, R. B. Ismail, and A. B. M. Desa, "Designing a smart transfer patient bed," in Innovation And Commercialization of Medical Electronic Technology Conference, pp. 111113, Selangor, Malaysia, November 2015.

[10] J. G. Boorman, S. Carr, and J. V. Kemble, "A clinical evaluation of the air-fluidised bed in a general plastic surgery unit," British Journal of Plastic Surgery, vol. 34, no. 2, pp. 165-168, 1981.

[11] P. Milward, M. Poole, and T. Skitt, "Tissue viability. Pressure sore prevention: scoring pressure sore risk in the community," Nursing Standard, vol. 8, no. 7, p. 50, 1993.

[12] D. M. Chaloner and P. J. Franks, "Validity of the Walsall community pressure sore risk calculator," The British Journal of Nursing, vol. 5, no. 6, pp. 266-276, 2000, 268, 270, 272.

[13] D. G. Gray, P. J. Cooper, and M. Campbell, “A study of the performance of a pressure reducing foam mattress after three years of use," Journal of Tissue Viability, vol. 8, no. 3, pp. 913, 1998.

[14] M. E. Collier, "Pressure-reducing mattresses," Journal of Wound Care, vol. 5, no. 5, pp. 207-211, 1996.

[15] D. Gray and M. Campbell, "A randomised clinical trial of two types of foam mattresses," Journal of Tissue Viability, vol. 4, no. 4, pp. 128-132, 1994.

[16] D. Gray and M. Palk, "A clinical evaluation of the Transfoam mattress after 4 years," The British Journal of Nursing, vol. 9, no. 14, pp. 939-942, 2014.

[17] D. Gray, S. Whelan, G. Russell, and N. Balura, "Evaluation of an electric bed frame and pressure-reducing mattresses," 
British Journal of Community Nursing, vol. 5, no. 12, pp. 596$602,2000$.

[18] Z. Zhou, J. Cheng, W. Wei, and L. Lee, "Validation of evaluation model and evaluation indicators comprised Kansei engineering and eye movement with EEG: an example of medical nursing bed," Microsystem Technologies, vol. 27, no. 11, pp. 1317-1333, 2018.

[19] M. D. Shieh, Y. Li, and C. C. Yang, "Comparison of multiobjective evolutionary algorithms in hybrid Kansei engineering system for product form design," Advanced Engineering Informatics, vol. 36, pp. 31-42, 2018.

[20] M. Matell, "Is there an optimal number of alternatives for Likert scale items? Study I: reliability and validity," Educational and Psychological Measurement, vol. 31, no. 3, pp. 657-674, 1971.

[21] V. Venkatraman, J. W. Payne, and S. A. Huettel, “An overall probability of winning heuristic for complex risky decisions: choice and eye fixation evidence," Organizational Behavior and Human Decision Processes, vol. 125, no. 2, pp. 73-87, 2014.

[22] J. O. Berger, "Statistical decision theory and Bayesian analysis," Springer Science \& Business Media, vol. 83, no. 401, p. 266, 1993.

[23] R. Mcgill, J. W. Tukey, and W. A. Larsen, "Variations of box plots," The American Statistician, vol. 32, no. 1, pp. 12-16, 1978.

[24] P. B. Patnaik, "The non-central $\mathrm{chi}^{2}$ - and F-distributions and their applications," Biometrika, vol. 36, Part 1-2, pp. 202232, 1949.

[25] D. J. White, "Reactivity of fluoride dentifrices with artificial caries," Caries Research, vol. 22, no. 1, pp. 27-36, 1988.

[26] E. S. Pearson and H. O. Hartley, "Charts of the power function for analysis of variance tests, derived from the non-central $F$ distribution," Biometrika, vol. 38, no. 1-2, pp. 112-130, 1951.

[27] H. Huynh and L. S. Feldt, "Taylor and Francis online: conditions under which mean square ratios in repeated measurements designs have exact F-distributions," Journal of the American Statistical Association, vol. 65, no. 332, pp. 15821589, 1972.

[28] B. Bushman, "A procedure for combining sample standardized mean differences and vote counts to estimate the population standardized mean difference in fixed event models," Psychological Methods, vol. 1, no. 1, pp. 66-80, 1996. 